\title{
Designing to Promote Comprehension of Patients' Current Medications -Pharmacy Notebook
}

J Gen Intern Med 36(3):813-4

DOI: $10.1007 / \mathrm{s} 11606-020-06372-2$

(C) Society of General Internal Medicine 2021

I read with great interest Green and colleague's deprescribing intervention for patients with dementia and multiple chronic conditions. ${ }^{1}$ In addition to the risk of polypharmacy such as increasing their risk of adverse drug events, another problem could be difficulty for providers to know which medications patients are taking, especially when they need to go to multiple specialties. While electronic medical records can improve patients' care since it increases the transparency between health care providers and pharmacists, ${ }^{2}$ it does not involve the patients themselves, which is not helpful in improving patients' participation and understanding of their treatment plan. In addition, health care providers could not recognize what patients are actually taking at home.

In Japan, patients have a pharmacy notebook, a wallet-size notebook that provides the medications, doses as well as the dispensing hospital and prescribers name (Fig. 1). ${ }^{3}$ This helps promote patients' comprehension about their diseases by providing an easily transportable document that comprehensively updates the patient's current medications (e.g., holding antihypertensive medications due to hypotension per a patient's decision, planning to stop medication such as clopidogrel after one year of percutaneous coronary intervention per a physician's decision).

I agree that we need to decrease the number of medications for patients with polypharmacy. Interventions like Green et al. could be assisted by our pharmacy notebook system, which clarifies for all members of the care team what medications the patients are taking as well as patients and their caregivers.
8/25/2020 Toshiki Kuno MD, PhD Department of Medicine, Mount Sinai Beth Israel

1 Aspirin 81mg QD x $90 \mathrm{~d}$

Coronary artery disease

2 Atorvastatin 80mg QD $\times 90 \mathrm{~d}$ Hyperlipidemia

3 Coreg $25 \mathrm{mg}$ BID $\times 90 \mathrm{~d} \begin{gathered}\begin{array}{c}\text { Patien's memo } \\ \text { Not taking due to }\end{array} \\ \text { Con }\end{gathered}$ Coronary artery disease 4 Lisinopril 10mg QD x $90 \mathrm{~d}$ Hypertension

5 Clopidogrel 75mg QD x $30 \mathrm{~d}$

(stop after $9 / 25 / 20$ )

Coronary artery disease

$8 / 27 / 20 x x x \times x x$ MD

Department of Neurology, Mount Sinai Beth Israel
1 Keppra 500mg BID x 90 d

Seizure

8/28/20 xxxx xxxx MD

Department of Endocrinology,

Mount Sinai Beth Israel

1 Metformin 1000mg BID x 90 d

Diabetes mellitus

2 Insulin Lantus 20 units bedtime

Diabetes Mellitus

3 Insulin Lispro 5 units TID

Diabetes Mellitus

$8 / 29 / 20 x x \times x$ MD

Department of Psychiatry, Mount

Sinai Beth Israel

1 Citalopram 10mg QD x $30 \mathrm{~d}$

Depression

Figure 1 An example of a pharmacy notebook.

Received August 3, 2020

Accepted November 25, 2020

Published online January 14, 2021 
Toshiki Kuno, $\mathrm{MD}, \mathrm{Ph} \mathrm{D}^{1}$

${ }^{1}$ Department of Medicine, Icahn School of Medicine at Mount Sinai, Mount Sinai Beth Israel,

New York, NY, USA

Corresponding Author: Toshiki Kuno, MD, PhD; Department of Medicine, Icahn School of Medicine at Mount Sinai, Mount Sinai Beth Israel, New York, NY, USA (e-mail: kunotoshiki@gmail.com).

\section{Compliance with Ethical Standards:}

Conflict of Interest: The author declares that he does not have a conflict of interest.

\section{REFERENCES}

1. Green AR, Boyd CM, Gleason KS, Wright L, Kraus CR, Bedoy R, et al. Designing a Primary Care-Based Deprescribing Intervention for Patients with Dementia and Multiple Chronic Conditions: a Qualitative Study. J Gen Intern Med. 2020. https://doi.org/10.1007/s11606-020-06063-y

2. Sabir FRN, Tomlinson J, Strickland-Hodge B, Smith H. Evaluating the Connect with Pharmacy web-based intervention to reduce hospital readmission for older people. Int J Clin Pharm. 2019;41(5): 1239-46.

3. Tayama Y, Miyake K, Kanazawa E, Kaneko T, Sugihara K, Toyomi A, et al. Current situation of drug information in the kindergarten and nursery teacher: a pilot study. Yakugaku Zasshi. 2009;129(5):617-22.

Publisher's Note: Springer Nature remains neutral with regard to jurisdictional claims in published maps and institutional affiliations. 